\title{
OJS OPEN

\section{INOVAR NO ENSINO DE GEOGRAFIA: RELATO DE EXPERIÊNCIA NO MODELO REMOTO EM UMA ESCOLA DA ZONA RURAL DE SANTANA DO MATOS/RN}

\author{
Geovar Miguel dos Santos ${ }^{1}$, Julliana Araújo da Silva², Bárbara de Medeiros Dantasª ${ }^{3}$ Tânia \\ Cristina Meira Garcia ${ }^{4}$
}

\begin{abstract}
${ }^{1}$ Discente do Programa de Pós-Graduação em Geografia - GEOPROF da Universidade Federal do Rio Grande do Norte - UFRN/CERES. E-mail:geovar17@ gmail.com- ORCID: https://orcid.org/0000-0002-5186-8841

2 Discente do curso de Pedagogia pela Universidade Federal do Rio Grande do Norte - UFRN. E-mail: julliana.uern@outlook.com - ORCID: https://orcid.org/0000-0001-5606-110X

${ }^{3}$ Discente da Pós-Graduação do curso de Políticas Públicas e Projetos Sociais pela Faculdade de Venda Nova do Imigrante - FAVENI. E-mail: barbaradantas9@ hotmail.com - ORCID: https://orcid.org/0000-0003-0968-9476

${ }^{4}$ Professora associado da Universidade Federal do Rio Grande do Norte; E-mail: taniagmr@hotmail.com ORCID: https://orcid.org/0000-0002-5488-3684
\end{abstract}

Artigo recebido em 10/09/2020 e aceito em 18/06/2021

\begin{abstract}
RESUMO
Este trabalho trata-se de um relato de experiência desenvolvido com os estudantes da turma do $5^{\circ}$ ano do Ensino Fundamental em uma escola da zona rural, na cidade de Santana do Matos/RN. A prática pedagógica desenvolvida com os alunos gravitou em torno do processo de modernização das atividades econômicas, meios de comunicação e de transporte, e visava responder ao seguinte questionamento: de que maneira o avanço tecnológico contribui para a modernização das atividades humanas? Para a realização desta proposta de intervenção escolar foram desenvolvidas atividades de forma síncrona, em que utilizamos o aplicativo do Google Meet e de forma assíncrona, pelos aplicativos Google Classroom e WhatsApp, assim, esta intervenção esteve ancorada na metodologia da sala de aula invertida, na qual encontramos seus fundamentos conceituais e teórico-descritivo nos escritos de Jonathan Bergmann e Aaran Santos (2018), e de ensino remoto, com base em Garcia et. al (2020). Metodologicamente, foi realizada uma pesquisa bibliográfica e se fez o uso do diário de campo e de registros fotográficos. Com tal relato, é notável que em meio ao contexto do distanciamento social em decorrência da pandemia que assolou o mundo neste início de década, as metodologias ativas se apresentam como solução para propor práticas pedagógicas que visam formar o aluno no ensino de Geografia sob uma perspectiva crítica e reflexiva, de maneira a encurtar distâncias e oportunizar aprendizados.
\end{abstract}

Palavras-chave: inovação; Ensino Remoto e Emergencial; prática pedagógica; Ensino de Geografia; Zona Rural. 


\title{
INNOVATE IN TEACHING GEOGRAPHY: REPORT OF EXPERIENCE IN THE REMOTE MODEL IN A SCHOOL IN THE RURAL AREA OF SANTANA DO MATOS/RN
}

\begin{abstract}
This work is an experience report developed with the students of the 5th grade of elementary school in a rural school, in the city of Santana do Matos / RN. The pedagogical practice developed with the students revolved around the process of modernizing economic activities, means of communication and transportation, and aimed to answer the following question: how does technological advances contribute to the modernization of human activities? In order to carry out this school intervention proposal, activities were developed synchronously, using the Google Meet application and asynchronously, by the Google Classroom and WhatsApp applications, thus, this intervention was anchored in the inverted classroom methodology, in which we find its conceptual and theoretical-descriptive foundations in the writings of Jonathan Bergmann and Aaran Santos (2018), and of remote teaching, based on Garcia et. al (2020). Methodologically, a bibliographic research was carried out and the field diary and photographic records were used. With such a report, it is notable that in the context of social distance due to the pandemic that has plagued the world in the beginning of the decade, active methodologies are presented as a solution to propose pedagogical practices that aim to train students in Geography teaching from a perspective critical and reflective, in order to shorten distances and provide learning opportunities.
\end{abstract}

Keywords: innovation. Remote and Emergency Education. pedagogical practice. Geography Teaching. Countryside.

\section{INTRODUÇÃO}

Vive-se em um mundo altamente conectado através da rede mundial de computadores, o que desencadeou uma série de rupturas, seja na forma como se trabalha ou como se aprende, bem como nos mais diversos âmbitos da vida social. Neste sentido, as práticas de ensino desenvolvidas nas escolas passam a operar sob uma nova égide, dentre elas a colaboração surge como um princípio norteador da formação estudantil.

Para que a colaboração ocorra é preciso que desde a formação básica - passando pela formação a nível superior ou até mesmo continuada - as pessoas possam vivenciar um processo de revolução do pensamento, revolução essa que algumas vezes ainda encontra resistência no chão da escola, no entanto, é preciso recomeçar, pois, o século XXI exige do cidadão novas competências e habilidades para a sua atuação no campo profissional, estudantil ou social.

Neste novo começo, mais do que nunca, a aprendizagem deve ser tônica e constante nos projetos das instituições educacionais, a qual destacamos o exemplo de escolas que inovam em seu modo de fazer e pensar a educação, como é o caso da Escola da Ponte, em Portugal e da Escola Projeto Âncora, no Brasil, dentre inúmeras outras. Assim, para inovar, mudanças 
precisam acontecer na sala de aula e principalmente nas concepções educacionais. Alguns caminhos possíveis ocorrem através da criatividade, mediados pelas novas tecnologias, sempre respaldados em feedbacks que situam o aluno no seu percurso formativo, de forma a pontuar seus acertos e erros, de maneira a possibilitar uma formação humana pautada no compromisso e a visar a autonomia dos agentes que estão dentro da comunidade educativa, em especial dos educandos.

Desse modo, a Revolução Industrial, que aconteceu entre o final do século XVIII e início do século XIX, foi um marco para a história, tendo em vista que contribuiu para a modernização das indústrias, bem como para transformar as relações de trabalho e de produção, além disso, foi um acontecimento igualmente fundamental para a ascensão das tecnologias. Neste sentido e de forma a reconhecer que elas são utilizadas desde os primórdios pela humanidade, enquanto ferramentas rudimentares, partimos do pressuposto de que as tecnologias são necessárias e indispensáveis para o desenvolvimento das habilidades humanas.

Portanto, este artigo vem problematizar o uso das tecnologias como ferramentas capazes de oportunizar a inovação na sala de aula através do formato de ensino remoto, o qual se fez necessário mediante o contexto de pandemia ${ }^{1}$ que assolou o mundo neste início de década. Para tanto, se tem como objetivo relatar a experiência de uma sequência didática pautada no modelo do ensino remoto e na sala de aula invertida, desenvolvida numa escola da rede pública municipal, situada na zona rural de Santana do Matos-RN.

A referida sequência estimou que os alunos refletissem, mediante seus conhecimentos de mundo, a respeito da seguinte questão: de que maneira o avanço tecnológico contribui para a modernização das atividades humanas? Para que tal problema fosse resolvido, foi desenvolvido um plano de ensino em que foram articulados os objetivos propostos para a sequência didática junto a uma metodologia que teve por base o princípio dos métodos ativos mediados pelas Tecnologias de Informação e Comunicação (TIC's).

Em relação à metodologia deste trabalho, foi realizada uma pesquisa bibliográfica para fundamentar a sequência didática e nortear a prática docente, bem como para servir como aporte

\footnotetext{
${ }^{1}$ Mediante a Organização Mundial da Saúde (OMS), pandemia é "a disseminação mundial de uma nova doença", em que o novo Coronavírus (SARS-CoV-2) começou a se alastrar pelo planeta em meados de dezembro de 2019, quando em Whuan, na China, foi denominado como COVID-19. A transmissão ocorre pela proximidade entre pessoas, das gotículas expelidas por quem estiver infectado e os sintomas variam dos mais leves aos mais graves. Até o presente momento (setembro de 2020) não foi criada uma vacina eficaz, a única solução é o distanciamento social, além do uso de máscara ao sair e do álcool $70^{\circ}$ INPM. (Dados coletados no site do Ministério da Saúde https://coronavirus.saude.gov.br/).
} 
teórico deste artigo. Como instrumento de pesquisa, foi utilizado o diário de campo, em que ao final de cada aula eram registradas as impressões de cada intervenção. Foram também realizados registros fotográficos das aulas através dos diversos Ambientes Virtuais de Aprendizagem (AVA) utilizados para a prática pedagógica no modelo do ensino remoto.

Estruturalmente, este artigo está organizado da seguinte forma, no primeiro tópico problematiza-se a respeito da necessidade de inovar na educação frente ao contexto do desenvolvimento tecnológico e da pandemia mundial que modificou a rotina de todos os estudantes, professores e demais profissionais da educação. Em seguida, se apresenta o modelo de sala de aula invertida, que serviu como base para a intervenção pedagógica no modelo de ensino remoto. Logo após é apresentado o relato de experiência desenvolvido com uma turma dos anos iniciais do Ensino Fundamental, de modo a trazer à baila as práticas desenvolvidas e os resultados alcançados neste contexto de distanciamento social e de paralisação das aulas presenciais. Por fim, estão expostas as considerações finais a respeito do trabalho desenvolvido, seguido das devidas referências que serviram como guia para a fundamentação das ideias aqui levantadas e devidamente debatidas.

\section{INOVAR NA EDUCAÇÃO: UMA NECESSIDADE NOS DIAS ATUAIS}

O avanço tecnológico e suas inovações trouxeram vastas modificações no modo como o ser humano se relaciona com o mundo, em seu sentido político, econômico, social, cultural e educativo. As possibilidades ocasionadas pelas tecnologias são diversas, as atividades humanas mais facilmente desenvolvidas com auxílio dos recursos mais modernos.

Diante do progresso desenfreado das tecnologias na sociedade contemporânea, no âmbito educacional inovar parece ser um verbo com significado desafiador e conflitante, pela complexidade de se pensar em alguma metodologia moderna e atrativa para o alunado, já que se supõe que eles dominam os recursos digitais bem mais que os professores.

Mediante as dificuldades advindas do uso das tecnologias digitais, Pierre Lévy coloca que: "Não há obstáculos. Todos os estudantes têm uma habilidade extraordinária para usar esse tipo de ferramenta. Agora, os professores têm que conhecer tão bem quanto as crianças. Sobretudo, isso tem que ser utilizado numa ótica de aprendizagem colaborativa [...]" (MESQUITA apud SCHNEIDER, 2015, p.77). A aprendizagem passa a ser colaborativa quando o professor, ao reconhecer que não é detentor do saber, permite aprender com seus 
alunos e não apenas ensiná-los, desta forma há uma troca de saberes e o aluno ganha protagonismo, domínio sobre a construção de seu conhecimento. Cabe ao professor buscar se capacitar e se qualificar para que esteja preparado para enfrentar e dominar as tecnologias necessárias para o ensino e aprendizagem, porque não é possível retroceder aos avanços e sim acompanhá-los.

O ano de 2020, em meio ao contexto de uma pandemia viral, modificou muitos dos hábitos humanos, dentre os mais impactantes, o distanciamento social. Com o fechamento das escolas e universidades e interrupção de aulas presenciais, mais uma preocupação veio à tona: como ficaria a aprendizagem escolar? Certamente, defasada. Do dia para a noite, se fez necessário que profissionais da educação se desdobrassem para colocar suas metodologias mais inovadoras em prática, por meio das aulas online, a partir daí as dificuldades surgiram, mais fortes para uns do que para outros. Neste sentido, de certa forma este ano veio para surpreender e colocar em pauta a fecunda discussão que se realiza em torno do tema sobre o uso das tecnologias digitais como facilitadoras do processo de ensino e aprendizagem.

Em meados de 1990, com a popularização dos computadores e da internet, Papert (1994) discute a respeito da Era da Informática, pois ele se preocupa em como as inovações tecnológicas podem contribuir para melhorar o ambiente de aprendizagem das crianças. Lévy complementa essa linha de pensamento ao discutir sobre o ciberespaço, "um novo meio de comunicação que surge da interconexão mundial dos computadores" (LÉVY, 1999, p.15). Este termo é utilizado para especificar o universo oceânico de informações o qual a sociedade contemporânea está inserida (LÉVY, 1999). Ressalta-se que essa temática é amplamente debatida em meio aos teóricos e pautas educacionais, a Base Nacional Comum Curricular (BNCC) coloca que vivemos na Cultura Digital (BRASIL, 2017), pela qual os jovens, além de principais consumidores dos suportes tecnológicos, adquirem engajamento para buscar conhecimentos por iniciativa própria.

Nunca houve uma geração com acesso a tantas informações como a atual. Há o bombardeamento de informações simultâneas, ao mesmo tempo que parece ser complexo filtrálas e isso é um problema, porque como menciona Morin (2003) "mais vale uma cabeça bemfeita, que bem cheia", ou seja, é melhor ter ideias organizadas, conferir-lhes sentido para se adquirir aprendizado com elas, do que embaralhar todo tipo de informações sem compreender nada advinda delas. O professor pode ser colaborador nesse aspecto, de forma a instigar o senso crítico do alunado sobre as informações válidas ou desnecessárias diante dessa sobrecarga de 
dados. Por isso, o educador é figura indispensável, peça chave nesse processo, por ser responsável de facilitar esse caminho.

Nesta perspectiva, apesar de a escola apresentar certa resistência para a mudança, se notam iniciativas para levar a inovação para o campo educacional. O ensino remoto é um exemplo disso, tendo em vista que em meio à situação pandêmica essa foi a solução emergencial sugerida pelo Ministério da Educação (MEC) e adotada por várias instituições para ofertar aulas, um formato totalmente digital, que pode acontecer por meio de atividades síncronas (online) ou assíncronas (desconectadas), se utilizando plataformas disponíveis e gratuitas como o Google Meet, Google Classroom, Whatsapp - e de modo a respeitar a realidade de cada estudante.

As atividades remotas são desenvolvidas como uma forma inovadora de pensar e reinventar a educação escolar da atualidade. Por meio delas é possível haver o contato entre educador e educando, mesmo a distância, já que as tecnologias digitais auxiliam no processo de aproximar as pessoas, além de serem utilizadas para proporcionar o ensino e a aprendizagem escolar em meio a uma pandemia.

Destarte, a cibercultura (LÉVY, 1999), termo utilizado para descrever o espaço de convivência que se tem com as tecnologias e o modo como se interage com elas, é um ambiente que pode ser utilizado para aprender. Tendo em vista que há a democratização do acesso às informações, especialmente no contexto atual, esse lugar pode ser utilizado para inovar na educação. Dentre as diversas possibilidades de inovação dentro dessa rede, apresentar-se-á a sala de aula invertida enquanto uma metodologia que busca novas alternativas de ensinar e aprender com o auxílio das ferramentas digitais.

\section{SALA DE AULA INVERTIDA: UMA PROPOSTA INOVADORA}

$\mathrm{Na}$ busca pela inovação, por outras formas de se ensinar, diversas iniciativas emergem nas escolas, tais mudanças, em alguns cenários ainda são bastantes tímidas, em outros, não, como é o caso das iniciativas já explanadas na introdução deste trabalho e que foi amplamente discutido em algumas pesquisas científicas e que Santos (2017) vem apresentar em seus estudos monográficos.

Hoje já temos escolas que modificaram os processos de ensino e estão completamente centradas em métodos ativos, em que o estudante passa a ser o verdadeiro responsável pela sua 
aprendizagem e o professor como facilitador, ao qual irá guiar os alunos no oceano de informações que estão disponíveis na palma da mão, se fazendo necessário ter apenas um celular conectado à internet. Assim, em decorrência dos últimos avanços tecnológicos, a escola cada dia mais busca se reinventar para atender aos anseios de uma geração altamente conectada à rede mundial de computadores, que interage com os diversos espaços virtuais, sejam através das redes sociais ou dos diversos aplicativos disponíveis para os smartphones.

Neste contexto tecnológico, midiatizado e conectado, algumas metodologias de ensino ganham destaque mediante a forte aceitação pelos professores e principalmente pelos alunos, é o caso das propostas pautadas no ensino híbrido, em que mescla a experiência do presencial com o virtual. Neste arsenal de metodologias inovadoras, se destacam também outras, as quais citam-se o ensino por projeto, aprendizagem baseada em problemas (PBL), gamificação, design thinking e a sala de aula invertida, que será apresentada em mais detalhes a seguir e serviu de subsídio para a intervenção pedagógica relatada no próximo tópico.

Para compreender a sala de aula invertida, é preciso primeiro dizer que este modelo de ensino tem sua inspiração na realidade e nas verdadeiras necessidades dos alunos. Tal abordagem assume uma postura inversa, do ponto de vista filosófico, estratégico e prático, conforme ensina Bergmann e Sams (2018). Estes autores ainda afirmam que o modelo invertido ajuda os alunos a se saírem bem nas provas e consequentemente tirar boas notas, faz com que a aprendizagem seja maior e melhor, e possibilita o aprofundamento dos conhecimentos. Essa abordagem também impede que os alunos com suas especificidades, desejo de aprender e que não se encaixam em um único modelo de aprendizagem fiquem para trás, pois a sala de aula invertida possibilita a personalização do ensino.

Com base na prerrogativa de que nenhum aluno precisa do professor o tempo inteiro ao seu lado, pois isso não possibilitaria a autonomia do estudante, a sala de aula invertida faz com que o acesso aos conhecimentos de uma determinada aula sejam vistos em casa, através de videoaulas gravadas previamente pelos professores ou disponibilizadas em alguma plataforma de compartilhamento de vídeo, e até mesmo por outros recursos pedagógicos, como é o caso dos textos disponíveis em livros, sejam eles didáticos ou não. Dessa maneira, o que antes o estudante fazia em casa, que era a resolução de situações problemas, passa a ser feito exclusivamente em sala de aula, momento em que o aluno tem o professor a sua disposição para esclarecer equívocos em conceitos e determinados conhecimentos e até para explicar eventuais dúvidas ou questões norteadoras. 
É importante destacar que no modelo da sala aula invertida, Bergmann e Sams (2018) esclarecem que não basta apenas inverter o acesso ao conteúdo, é preciso que o currículo não seja imposto, pois os discentes podem fazer o uso de uma videoteca, da biblioteca ou de outros recursos disponíveis na escola e até mesmo na internet, para construir o seu conhecimento, de modo a se concentrarem aos tópicos que melhor convêm. Neste sentido, este modelo possibilita a criação de um sistema capaz de permitir que os alunos progridam no material sempre que avançar em seus aprendizados, em respeito ao seu próprio ritmo. No entanto, se faz oportuno dizer que "não existe uma única maneira de inverter a sala de aula - não há essa coisa de a sala de aula invertida. Não existe metodologia específica a ser aplicada, nem checklist a seguir que leve a resultados garantidos [...]" (BERGMANN; SAMS, 2018, p. 30).

Bergmann e Sams (2018) acreditam que a sala de aula invertida modifica a vida dos aprendizes, de forma a atender às expectativas de todos os níveis de ensino e as mais diversas áreas de conhecimento, pois "fala a língua dos estudantes de hoje" (p. 30). Neste sentido, é salutar dizer que os alunos compreendem com bastante naturalidade a aprendizagem digital e já faz parte da vida deles assistir às instruções oriunda de vídeos, sejam eles disponibilizados nos mais diversos canais no formato de tutorial ou outro formato de produção audiovisual.

$\mathrm{Na}$ sala de aula invertida os alunos podem acessar aos programas de estudos frente às suas verdadeiras necessidades e referente à escola no século XXI, no espaço educativo, os alunos podem e devem participar de diversas atividades em torno de temas de interesse, podem fazer o uso de diversos dispositivos digitais, trabalhar em equipe e utilizar os computadores para pesquisar ou desenvolver projetos com uso dos softwares, além de usar seus próprios smartphones e tablets nas aulas.

É importante ressaltar que no contexto de ensino remoto, o uso destas tecnologias, em especial dos aparelhos de celular, bem como os diversos aplicativos de comunicação e interação, passa a ser o principal meio de operacionalização da sala de aula, sendo assim, segundo Garcia et al. (2020, p. 9) a "comunicação com o aluno que poderá ser síncrona (em tempo real) ou assíncrona (em tempo diferente), assim como na sala de aula convencional." As autoras esclarecem que ensinar remotamente:

[...] não é sinônimo de ensinar a distância, embora esteja diretamente relacionado ao uso de tecnologia e, nesse caso, digital. O ensino remoto permite o uso de plataformas já disponíveis e abertas para outros fins, que não sejam estritamente os educacionais, assim como a inserção de ferramentas auxiliares e a introdução de práticas inovadoras. A variabilidade dos recursos e das estratégias bem como das práticas é definida a 
partir da familiaridade e da habilidade do professor em adotar tais recursos. Ensinar remotamente permite o compartilhamento de conteúdos escolares em aulas organizadas por meio de perfis [ambientes controlados por login e senha] criados em plataformas de ensino, como, por exemplo, SIGAA e MOODLE, aplicativos como Hangouts, Meet, Zoom ou redes sociais (GARCIA et al. 2020, p. 5).

Neste sentido, no ensino remoto para se fazer o uso da metodologia da sala de aula invertida, deve-se propor que os alunos desenvolvam as atividades de aproximação com os objetos do conhecimento de forma assíncrona e ao ter contato com o professor, nas aulas síncronas, possam esclarecer dúvidas e resolver problemas propostos pelo professor. É importante também ressaltar que no ensino remoto além de apresentar grandes potencialidades, há diversos desafios, conforme aponta Garcia et al (2020, p. 5), "que envolvem pessoas, tecnologias, expertise e infraestrutura".

$\mathrm{O}$ acesso aos diversos instrumentos tecnológicos, à rede mundial de computadores e a uma infinidade de informações, vem exigir do ensino de Geografia que o professor possa considerar, "além do debate necessário ao desenvolvimento crítico-social dos alunos, o uso de metodologias de ensino que busquem aproximar esses conteúdos do mundo concreto dos alunos, onde possam efetivamente tornar-se partícipes ativos e conscientes da construção da sociedade" (LIMA, SILVA e ARAÚJO, 2018, p. 1), uma vez que as crianças, os jovens e os adultos precisam ter habilidades para dominar os smartphones e possam administrar as informações, que estão cada vez mais rápidas e constantes, nos mais diversos canais de comunicação.

Neste sentido, o ensino de Geografia deve, de acordo com Lima, Silva e Araújo (2018, p. 1) "buscar problematizar situações, analisar as contradições do espaço e assim avançar para além da descrição das paisagens, do visível, e alcançar a construção de novos conceitos, utilizando-se de metodologias atrativas, criativas e inovadoras em sala de aula." Para tanto, o modelo de sala de aula invertida, por propor uma nova forma de aproximação com os objetos de conhecimentos da Geografia, oportuniza que o estudante construa seu saber geográfico, pautado na realidade em que está imerso, e problematizar junto ao docente questões latentes a sua formação, a sua curiosidade e ao seu interesse, de modo que os aprendizados façam verdadeiro sentido e que tais conhecimentos sejam úteis na transformação do espaço geográfico. 


\section{A PRÁTICA DESENVOLVIDA: RELATO DA EXPERIÊNCIA (A MODERNIZAÇÃO DAS ATIVIDADES HUMANAS)}

Ao considerar tudo o que foi relatado, aliado ao cenário que o país está inserido em razão da pandemia do novo Coronavírus, entende-se que o uso do ensino remoto foi a alternativa determinante para evitar a quebra total ou parcial do vínculo dos alunos e famílias com a escola. No desafio de manter os estudantes motivados e engajados nas aulas virtuais, optou-se por utilizar as metodologias ativas com ênfase na sala de aula invertida em todas as intervenções realizadas na disciplina de Geografia com a turma do $5^{\circ}$ ano do Ensino Fundamental de uma escola da zona rural, da cidade de Santana do Matos/RN.

Conforme Freire (1996, p. 29) escreveu, para que o ensino aconteça é necessário respeitar a autonomia do educando, "de nada serve, a não ser para irritar o educando e desmoralizar o discurso hipócrita do educador, falar em democracia e liberdade mas impor ao educando a vontade de arrogante do mestre”. Por essa e muitas outras razões se escolheu priorizar nas intervenções relatadas a seguir as metodologias ativas no ensino de Geografia, para proporcionar um espaço de protagonismo e participação direta dos alunos na construção do conhecimento geográfico.

Uma das décadas consideradas referenciais no processo de transformação e modernização de diversos setores no Brasil foi a de 50. O país viveu, no pós-guerra, um verdadeiro processo de mudanças significativas com alterações culturais, políticas e sociais. Neste contexto, estão inseridas as modernizações das atividades econômicas - agricultura, pecuária e extrativismo -, meios de comunicação e de transporte, conteúdos esses que foram abordados no decorrer das intervenções realizadas na turma do $5^{\circ}$ ano do Ensino Fundamental, relatadas a seguir.

A proposta inicial consistiu em disponibilizar, no Google Classroom (Figura 1), orientações e comunicados norteadores sobre a semana de intervenções, bem como o link que dava acesso à publicação de um vídeo no canal do Youtube do professor $\mathrm{G}^{2}$ (Figura 2), contendo uma apresentação geral da sequência de atividades, tarefas, divisão de grupos e conteúdos a serem vistos pela turma. A divisão dos grupos de estudos foram disponibilizadas no Google

\footnotetext{
${ }^{2}$ Com o intuito de preservar a identidade dos autores/professores envolvidos na intervenção, eles serão chamados pelas iniciais dos nomes: G, T, B e J.
} 
Classroom e no vídeo postado no Youtube, os discentes foram orientados a ler sobre os três conteúdos abordados no parágrafo anterior, destacar as principais partes e elaborar um resumo para enviar no grupo do WhatsApp da turma, entre às 16h e 17h (Figura 3), além de levarem as dúvidas e colocações para sala de aula remota com o objetivo de elaborar mapas conceituais dos conteúdos.

Figura 1 - Orientações gerais e divisão de tarefas
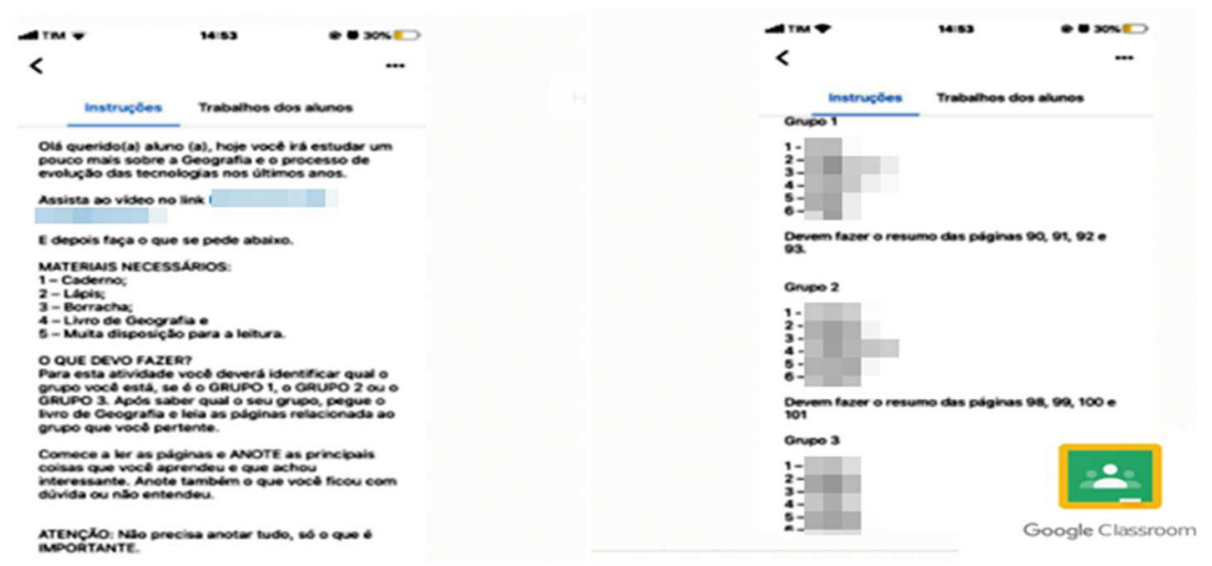

Fonte: Arquivo dos autores

Figura 2 - Vídeo postado no canal de um dos professores, no Youtube

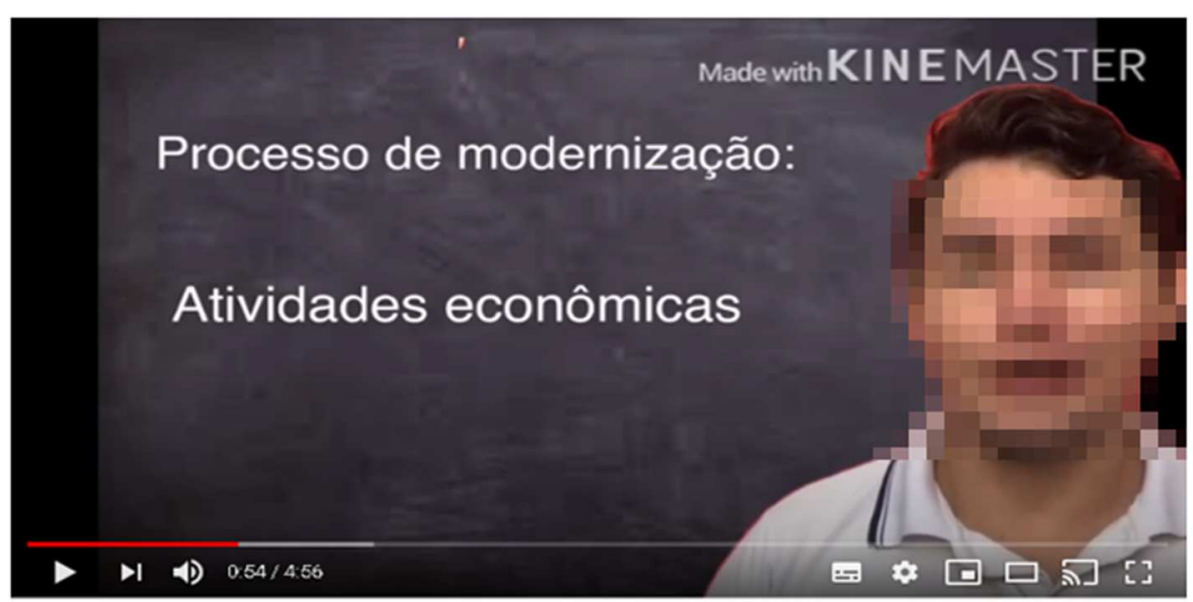

Fonte: Arquivo dos autores 
Figura 3 - Envio das tarefas feitas pelos alunos

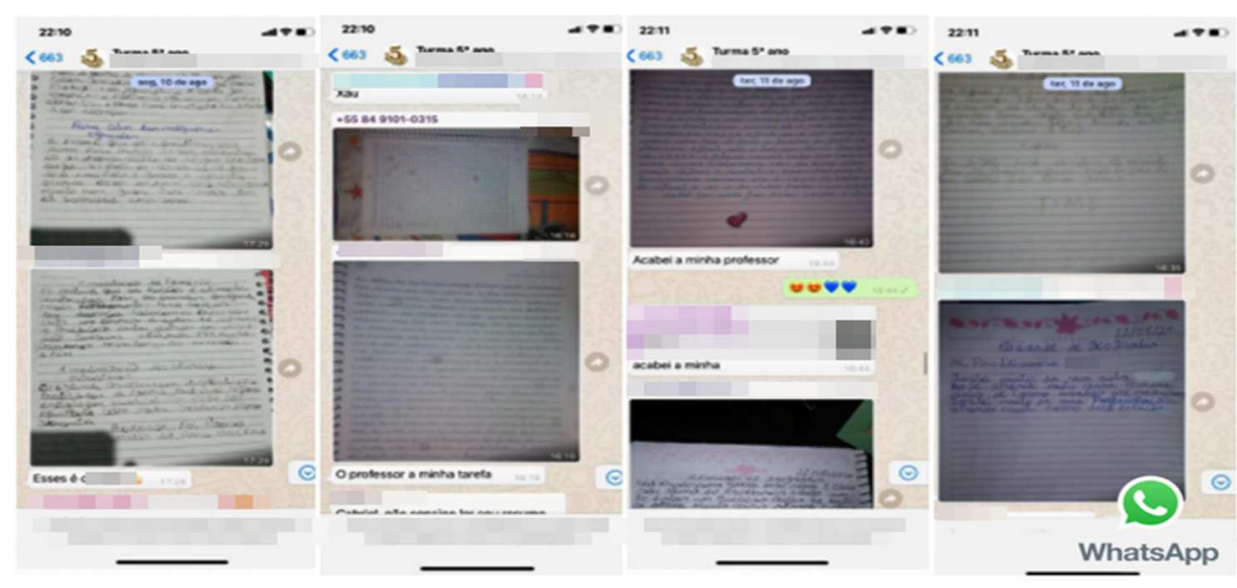

Fonte: Arquivo dos autores

Todas as figuras acima representam atividades desenvolvidas antes do contato síncrono com os alunos que se deu pela primeira vez na sala de aula remota através do Google Meet, e essa é justamente uma das características das metodologias ativas - promover o contato prévio do aluno com o conteúdo, para que ele chegue em sala de aula tendo noção do que vai ser trabalhado. Nesse caso, o processo de modernização no campo - agricultura, pecuária e extrativismo - foi a primeira temática abordada remotamente com os estudantes, de forma síncrona, no Google Meet e assíncrona, no Google Classroom e Youtube. O fato é que os estudantes já tinham um conhecimento prévio de vivência com o assunto, tanto por estarem inseridos no contexto rural, quanto pela orientação das leituras no livro didático de Geografia, repassadas como tarefa, através de texto no Google Classroom e de vídeo no canal no Youtube.

A implantação das novas tecnologias e maquinários no processo de produção no campo aconteceram de forma natural, gradativa e, posteriormente, científica. Algumas delas vivenciadas pelos bisavós, avós, pais ou até mesmo pelos próprios alunos. O meio técnicocientífico-informacional defendido por Milton Santos (1996) é retrato dessa sequência e através dele o autor enfatiza as fases dos processos de transformação da natureza e de construção do espaço geográfico, e o quanto um influencia no outro. Baseados nessa vertente, foi abordado na primeira intervenção sobre os processos de modernização na agricultura, pecuária e extrativismo.

A primeira aula remota aconteceu de forma síncrona, através do Google Meet, com a participação de 11 pessoas - sendo 8 alunos e 3 professores - (Figura 4), ou seja, faltaram 12 alunos para completar o número total da turma, o que já era previamente esperado pois alguns 
não possuem acesso ao smartphone na hora da aula e outros acabam por não entrar no momento da aula síncrona por falta de interesse. Após a apresentação dos professores, os alunos foram convidados a se identificar (nome, idade e comunidade que mora), para então começar a conversa sobre o conteúdo previamente lido e "resumido" do livro didático, a fim da construção do Mapa Conceitual (Figura 5) em conjunto, no site MindMeister, como previsto no Plano de Ensino, elencando as principais ideias presentes nos textos do livro.

Figura 4 - Registro da $1^{\mathrm{a}}$ aula remota de forma síncrona

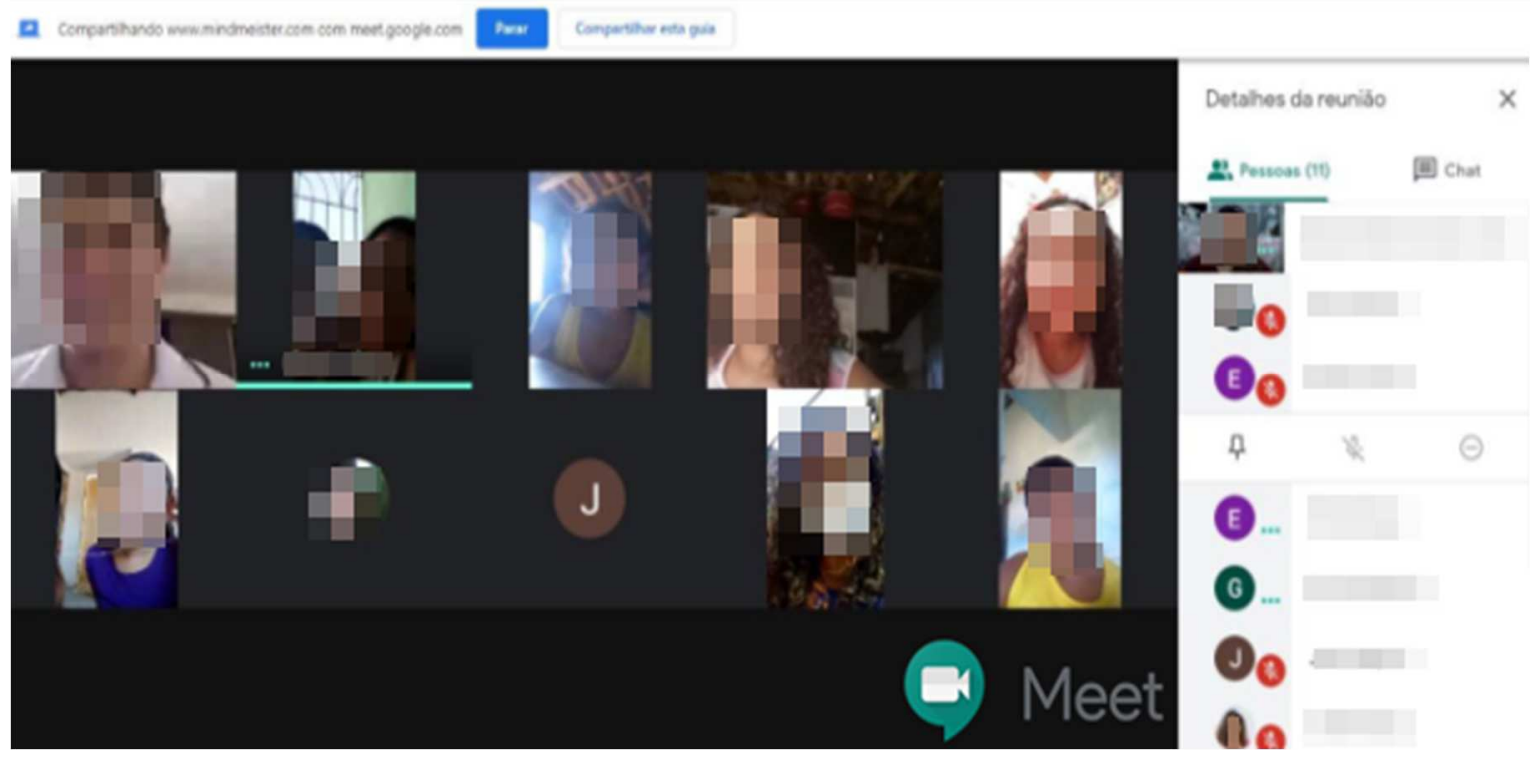

Fonte: Arquivo dos autores

Figura 5 -Mapa mental sobre a modernização na agricultura, pecuária e extrativismo

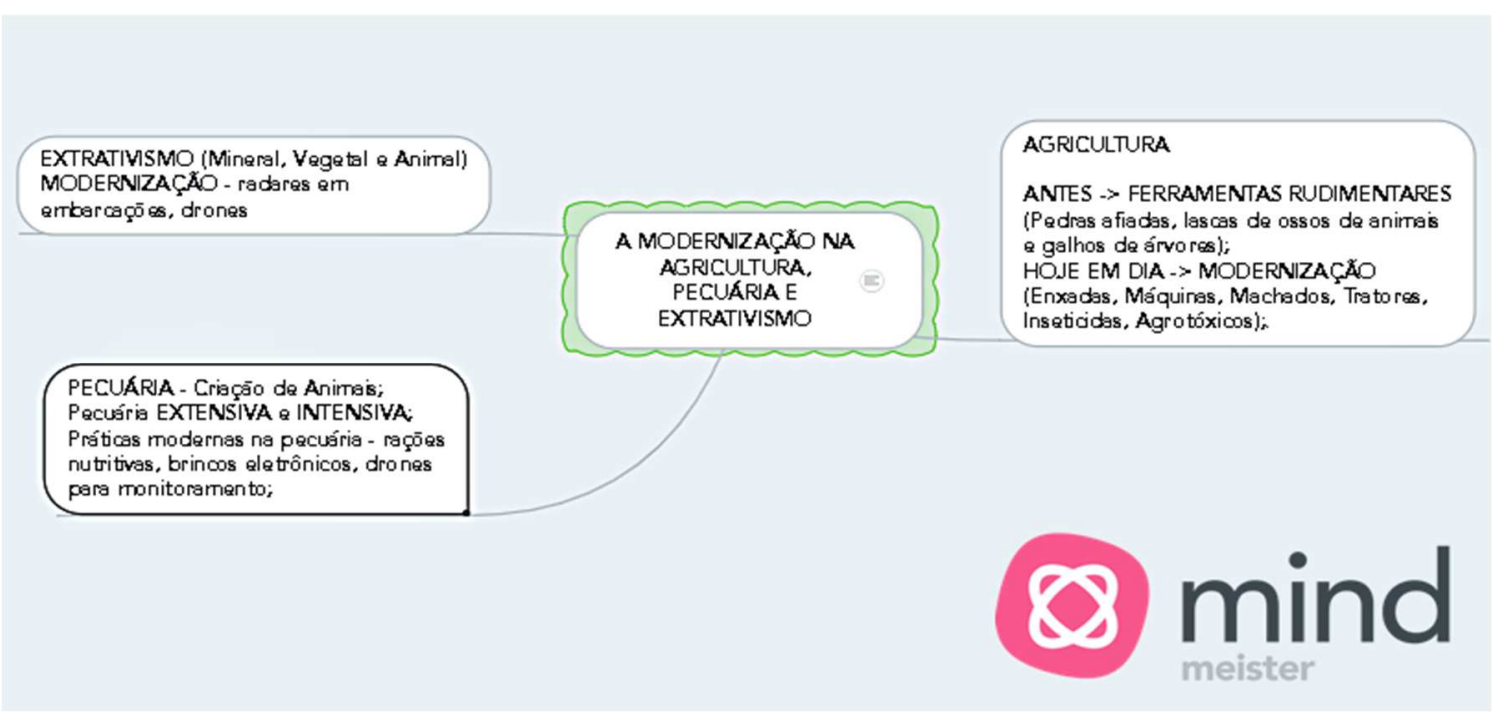

Fonte: Arquivo dos autores 
Observou-se uma boa interação dos alunos no decorrer da aula, especialmente do grupo que havia ficado responsável de ler as páginas referentes a discussão sobre a modernização na agricultura, pecuária e extrativismo, logo o tema tinha ligação com a realidade deles, em pequena escala - contexto rural. Deu-se por finalizada a primeira abordagem no primeiro dia e foi sugerido aos alunos a escrita e envio no grupo do WhatsApp de uma carta para a professora $\mathrm{T}$ (Figura 6), sobre o que tinham compreendido da primeira aula e do projeto como um todo.

Figura 6 - Carta escrita por aluna para a professora T, como proposta de tarefa da $1^{\mathrm{a}}$ aula

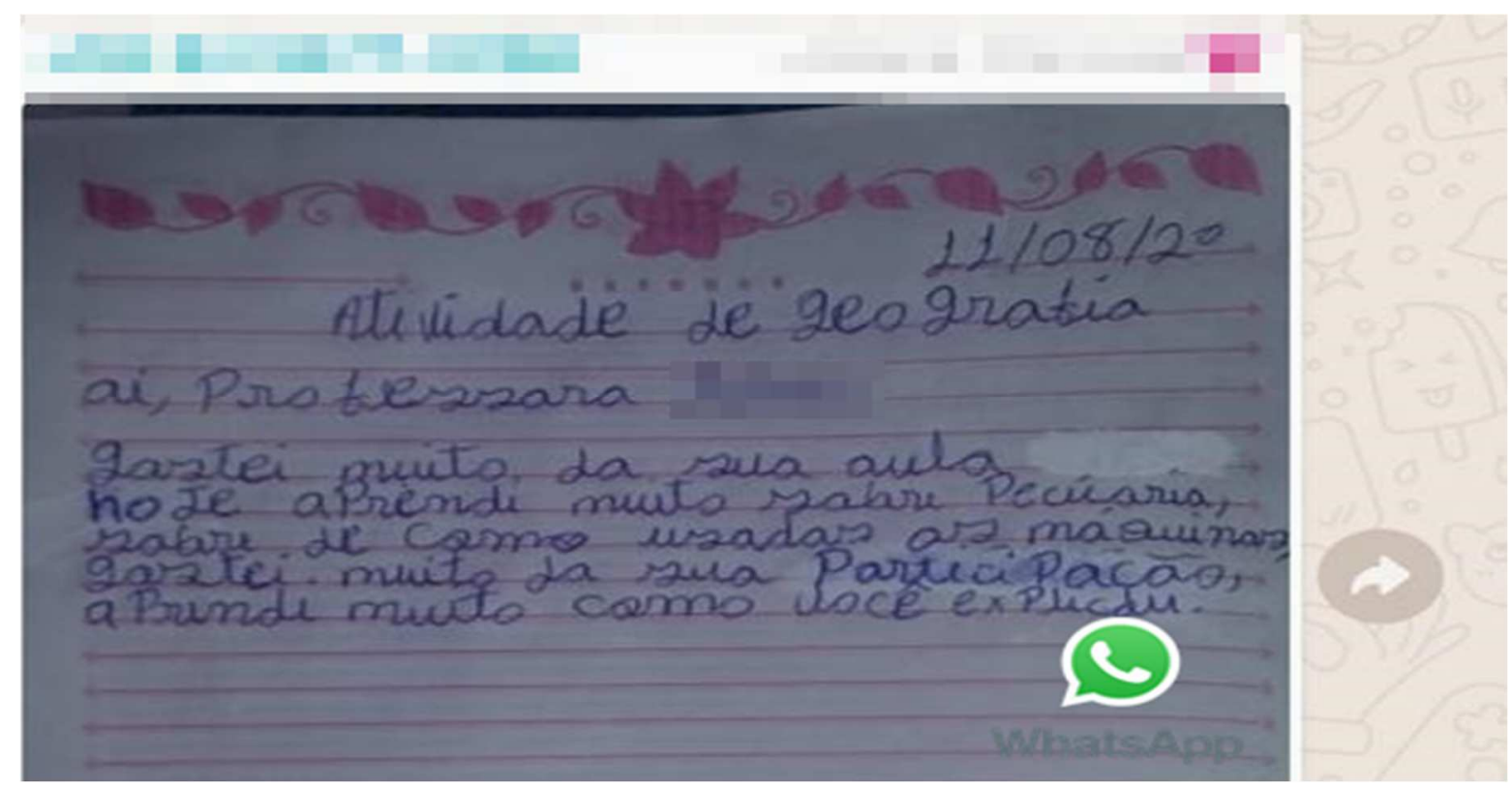

Fonte: Arquivo dos autores

Iniciou-se a segunda intervenção com um diálogo sobre a aula anterior e de modo a adentrar no desenvolvimento da capacidade de associar os conteúdos vistos com a realidade na qual os discentes estavam inseridos, a aprendizagem significativa (SANTOS, 2008), através de uma roda de conversa mediada pela professora $\mathrm{J}$, houve uma ótima participação dos alunos (Figura 6) que se envolveram de forma tão intensa na discussão que em alguns momentos era necessário retornar ao objetivo central da discussão para não perder a direção do planejado.

A partir desses momentos de escuta, na segunda aula remota (Figura 7), com participação de 8 alunos, alguns componentes do Grupo 2 relataram o que tinham previamente lido e resumido, conforme o combinado, para elaboração do Mapa Conceitual (Figura 8) sobre a modernização dos meios de transporte. A participação dos alunos foi muito positiva, pois a evolução do conteúdo também estava inserida na realidade as quais eles viam ou viviam - desde 
os meios de transportes carroçáveis até os aéreos -. Após a discussão dos meios de transporte, o Grupo 3 se encarregou de continuar o diálogo sobre a modernização dos meios de comunicação, culminando com a elaboração do Mapa Conceitual (Figura 9) para unir informações e facilitar a interpretação do conteúdo.

Figura $7-2^{\mathrm{a}}$ aula remota com destaque para a participação dos alunos

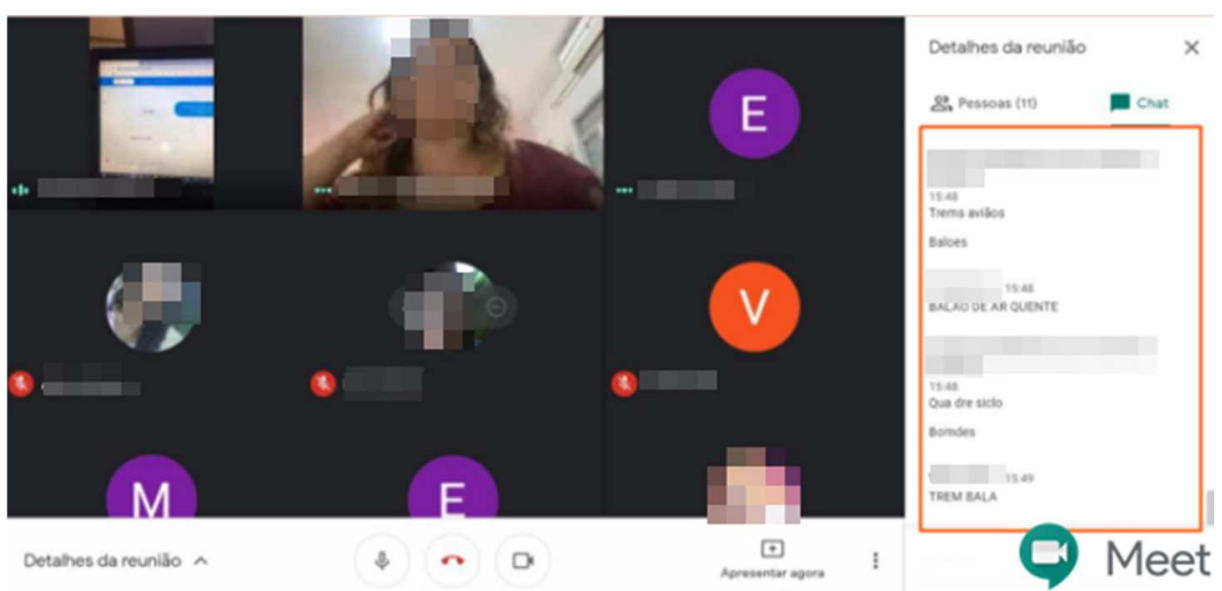

Fonte: Arquivo dos autores

Figura 8 - Mapa Conceitual elaborado com os alunos sobre os avanços nos meios de transportes

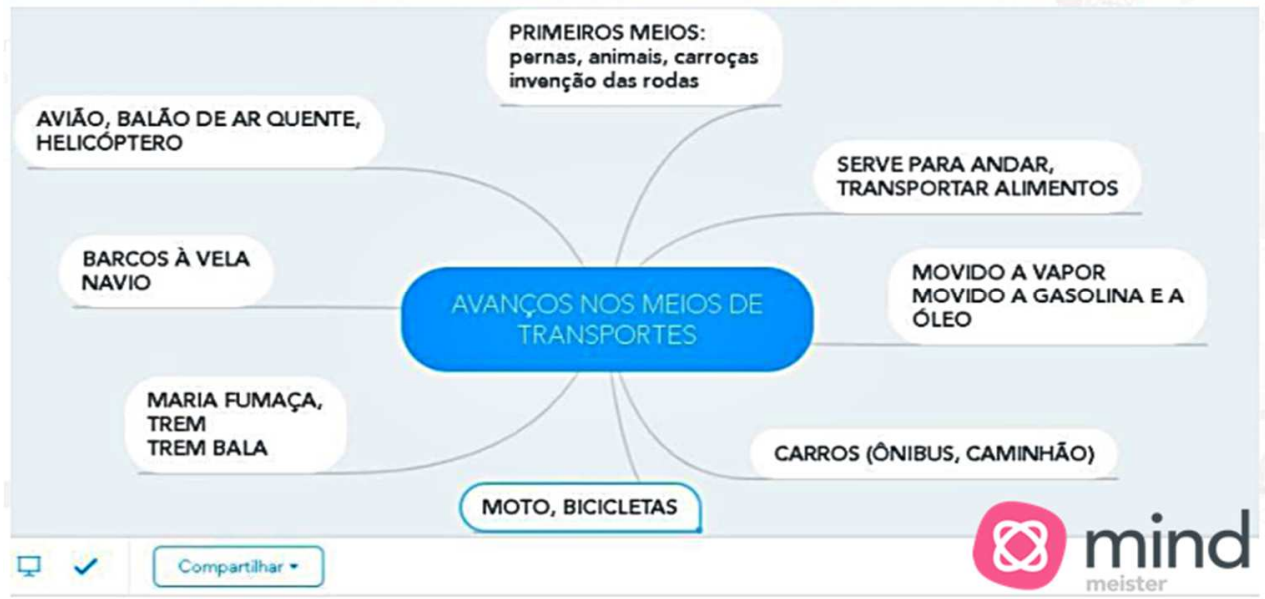

Fonte: Arquivo dos autores 
Figura 9 - Mapa Conceitual elaborado com os alunos sobre a modernização nos meios de comunicação

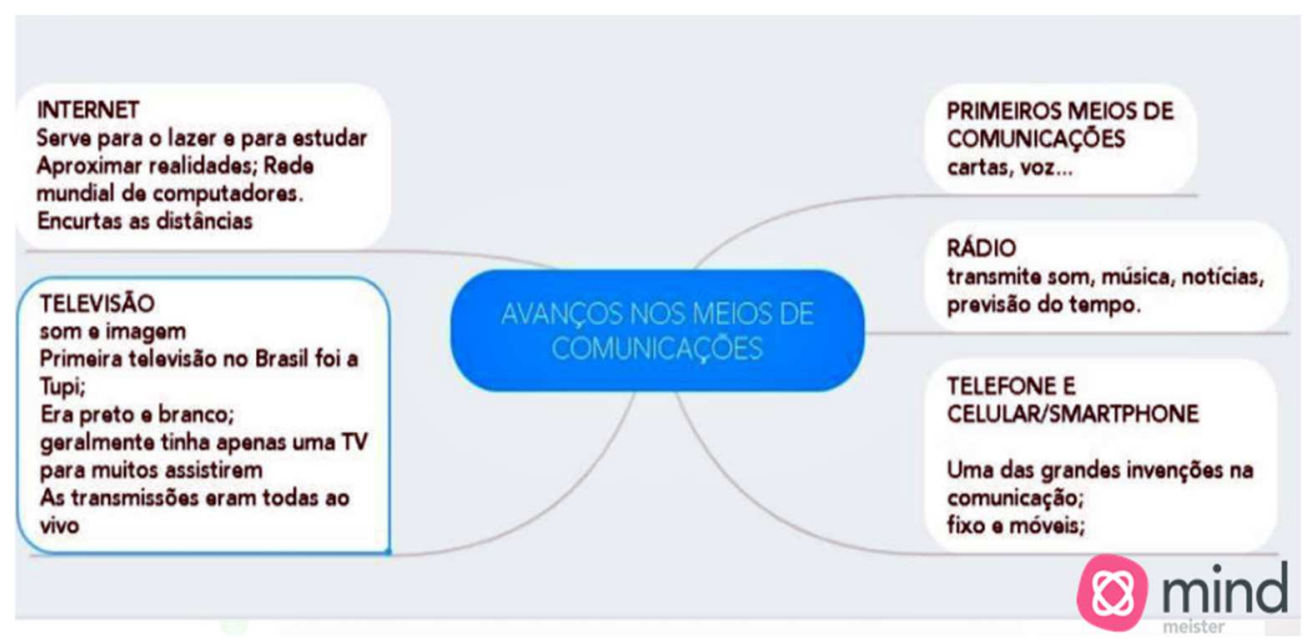

Fonte: Arquivo dos autores

Na sequência de intervenções, a última e terceira aulas remotas aconteceram com a participação de 8 alunos e inicialmente foi feita uma recapitulação e discussão dos conteúdos vistos no decorrer da semana, para rever os mapas conceituais feitos com a colaboração dos próprios alunos e, para encerrar, foi apresentado para os alunos o Manual Instrucional (Figura 10), elaborado pelos professores $\mathrm{G}, \mathrm{J}$ e B, com as orientações acerca da gravação de vídeos (iluminação, equipamentos, velocidade da fala, direção da câmera, aplicativo, entre outras). Com base nas orientações predispostas no Manual Instrucional, os alunos produziram vídeos narrando como aconteceu o processo de modernização no lugar onde vivem, na ótica deles, com auxílio dos pais ou parentes (seja na agricultura, pecuária e extrativismo, nos meios de comunicação ou transporte) e postaram no grupo do WhatsApp, como forma de comprovar que fizeram (Figura 11). 
Figura 10 - Manual Instrucional elaborado pelos professores para orientar os alunos
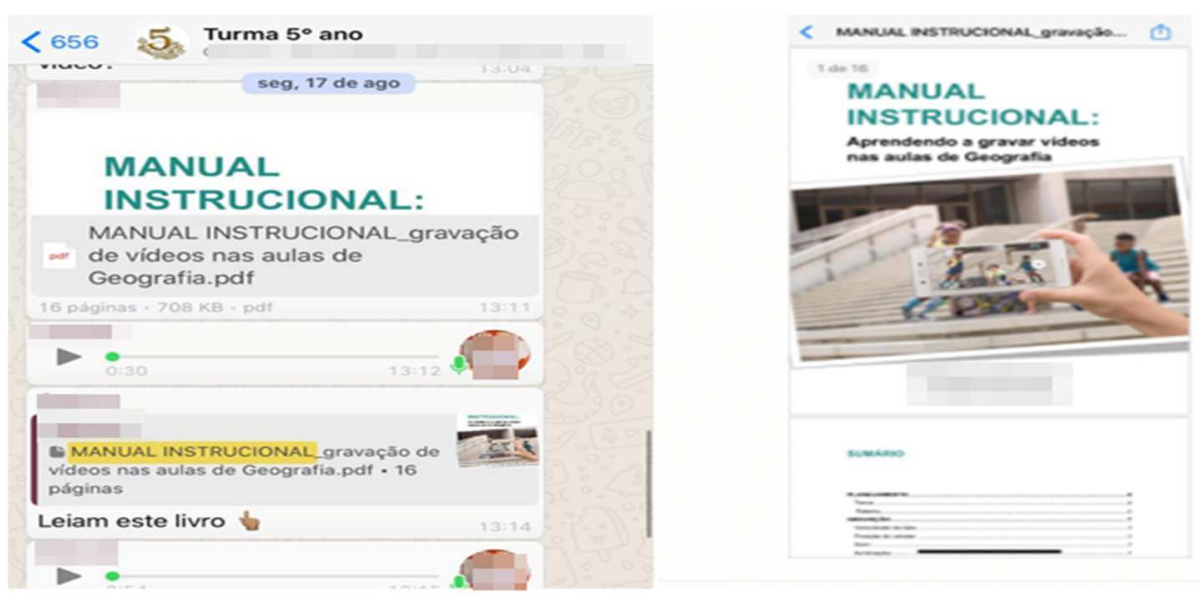

Fonte: Arquivo dos autores

Figura 11 - Vídeos produzidos pelos alunos enquanto atividade de fixação, bem como para avaliação da aprendizagem deles
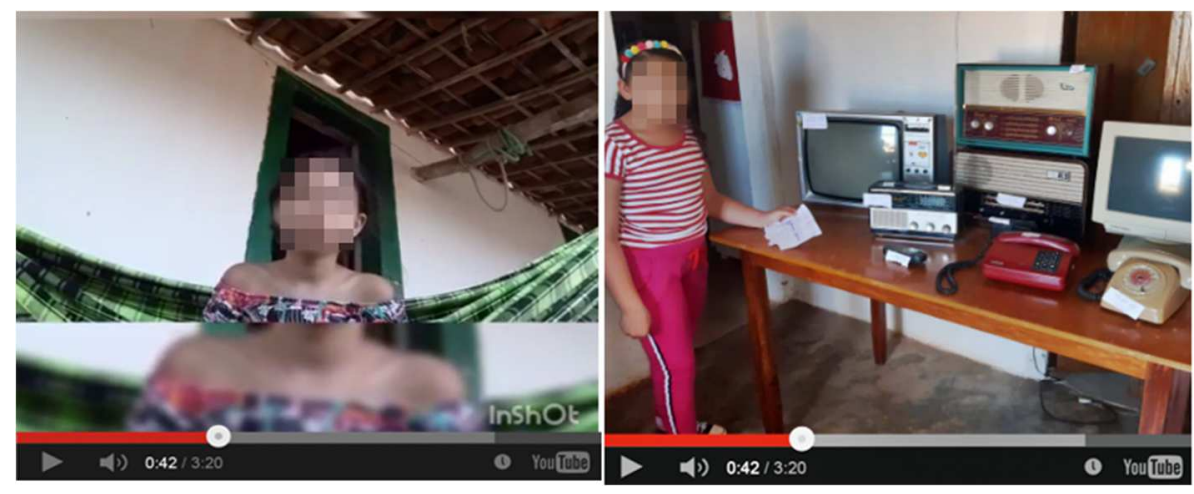

Fonte: Arquivo dos autores

Essa atividade foi muito positiva e essencial para a avaliação da compreensão do conteúdo por parte do aluno, que se deu quatro dias após o envio dos vídeos acima. Os resultados surpreenderam, pois a desenvoltura e criatividade dos alunos se sobressaíram, de maneira a desmistificar mais uma vez a ideia de que na Zona Rural não é possível acontecer o ensino remoto de fato. 


\section{CONSIDERAÇÕES FINAIS}

Inovar por meio dos recursos digitais aparece como algo necessário para o contexto atual. Com a pandemia, ocasionada pelo COVID-19, houve a urgência de mudança de hábitos, de forma que a educação também sofreu impactos. Percebemos mais do que antes as possibilidades de se utilizar os recursos tecnológicos para adquirir aprendizado.

Por meio do ensino remoto, foi descoberta uma diversidade de plataformas para promover o ensino, aprendizagem e além de tudo a comunicação interpessoal entre educador e educando, nas quais se encontram alternativas de dar continuidade e incentivar a busca pelo conhecimento.

A metodologia da sala de aula invertida oportuniza aos alunos a independência de construir o próprio conhecimento, uma vez que está ancorada no método de ensino ativo. Em relação à gestão de classe, buscou-se evidenciar essa autonomia do alunado, de modo que a todo momento foi incentivada a participação deles por meio de questões norteadoras.

Para a formação dos professores-pesquisadores, a experiência foi inspiradora, no sentido de utilizar as tecnologias digitais para relacionar ensino e aprendizagem de uma maneira didática e dinâmica. Pode-se afirmar com convicção que a educação foi repensada e revolucionada em decorrência da situação atual.

Neste sentido, também pode-se dizer que a experiência aqui desenvolvida qualificou os professores-pesquisadores para atuar em um formato de ensino remoto, que utiliza os meios tecnológicos para viabilizar estratégias de ensino neste período pandêmico

\section{REFERÊNCIAS}

BERGMANN, J; SAMS, A. Sala de aula invertida: uma metodologia ativa de aprendizagem. Tradução de Afonso Celso da Cunha Serra. Rio de Janeiro: LCT, 2018.

BRASIL. Base Nacional Comum Curricular. Brasília: MEC/Secretaria de Educação Básica, 2017.

FREIRE, P. Pedagogia da autonomia: saberes necessários à prática educativa. $27^{\mathrm{a}}$ ed. São Paulo: Paz e Terra, 1996

GARCIA. T. C. M; MORAIS, I. R. D; ZAROS, L. G; RÊGO, M. C. F. D. Ensino remoto emergencial: proposta de designer para organização de aulas. Natal: SEDIS/UFRN, 2020. 
Disponível em <https://repositorio.ufrn.br/jspui/handle/123456789/29767> Acessado em 01 de setembro de 2020.

LÉVY, P. Cibercultura. Tradução de Carlos Irineu da Costa. São Paulo: 34, 1999.

LIMA, A. E. F; SILVA. D. R da; ARAÚJO, E. F. de. Metodologias ativas em geografia: experiências docentes do Instituto Federal de Educação, Ciência e Tecnologia (IFCE).

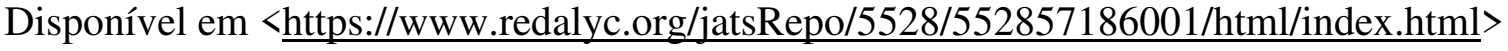
Acessado em 07 de setembro de 2020.

MORAN, J. M. Mudando a educação com metodologias ativas. Convergências Midiáticas, Educação e Cidadania: aproximações jovens. Coleção Mídias Contemporâneas, 2015 Disponível em http://www2.eca.usp.br/moran/wpcontent/uploads/2013/12/mudando_moran.pdf

MORIN, E. A cabeça bem-feita: repensar a reforma, reformar o pensamento. Tradução de Eloá Jacobina. $8^{\mathrm{a}}$ ed. Rio de Janeiro: Bertrand Brasil, 2003.

PAPERT, S. A máquina das crianças: repensando a escola na era da informática. Trad.: Sandra Costa. Porto alegre: Artes Médicas, 1994

SANTOS, G. M. dos; Experiências Inovadoras: aspectos filosóficos e metodológicos da Escola Projeto Âncora, Escola da Ponte e Pedagogia Waldorf. UFRN, 2017. Disponível em $<$ https://monografias.ufrn.br/jspui/handle/123456789/4380> Acessado em 01 de setembro de 2020.

SANTOS, J. C. F. dos. Aprendizagem Significativa: modalidades de aprendizagem e o papel do professor. Porto Alegre: Mediação, 2008.

SANTOS, M. A natureza do espaço: técnica e tempo, razão e emoção. São Paulo: Ed. Hucitec, 1996.

SCHNEIDER, F. Organização do espaço escolar por meio do modelo de ensino híbrido. In: BACICH, L.; TANZI NETO, A.; TREVISANI, F. de M. [orgs]. Ensino Híbrido: personalização e tecnologia na educação. Porto Alegre: Penso, 2015. (p. 67-80). 